\section{Pacific Northwest \\ National Laboratory \\ Operated by Battelle for the U.S. Department of Energy}

PNNL-13066

UC-2030

\title{
Buoyant Response of the Tank 241-SY-101 Crust to Transfer and Back-Dilution
}

C. W. Stewart

October 1999

Prepared for the U.S. Department of Energy under Contract DE-AC06-76RLO 1830

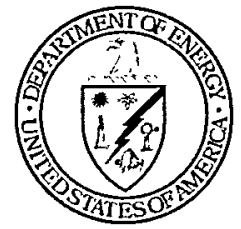




\title{
DISCLAIMER
}

This report was prepared as an account of work sponsored by an agency of the United States Government. Neither the United States Government nor any agency thereof, nor Battelle Memorial Institute, nor any of their employees, makes any warranty, express or implied, or assumes any legal liability or responsibility for the accuracy, completeness, or usefulness of any information, apparatus, product, or process disclosed, or represents that its use would not infringe privately owned rights. Reference herein to any specific commercial product, process, or service by trade name, trademark, manufacturer, or otherwise does not necessarily constitute or imply its endorsement, recommendation, or favoring by the United States Government or any agency thereof, or Battelle Memorial Institute. The views and opinions of authors expressed herein do not necessarily state or reflect those of the United States Government or any agency thereof.

\author{
PACIFIC NORTHWEST NATIONAL LABORATORY \\ operated by \\ BATTELLE \\ for the \\ UNITED STATES DEPARTMENT OF ENERGY \\ under Contract DE-AC06-76RLO 1830
}




\section{DISCLAIMER}

Portions of this document may be illegible in electronic image products. Images are produced from the best available original document. 


\section{Buoyant Response of the SY-101 Crust to Transfer and Back-Dilution}

C. W. Stewart

October 1999

Prepared for

the U.S. Department of Energy

under Contract DE-AC06-76RLO 1830

Pacific Northwest National Laboratory

Richland, Washington 


\section{Summary}

The mixer pump installed in Hanford Tank 241-SY-101 (SY-101) in July 1993 has prevented the large buoyant displacement gas release events (BD GRE) it has historically exhibited. But the absence of periodic disruption from GREs and the action of mixing have allowed the crust to grow. The accelerated gas retention has resulted in over 30 inches of waste level growth and the flammable gas volume stored in the crust has become a hazard. To remediate gas retention in the crust and the potential for buoyant displacement gas releases from below the crust, SY-101 will be diluted in the fall of 1999 to dissolve a large fraction of the solids in the tank. The plan is to transfer waste out and back-dilute with water in several steps of about 100,000 gallons each. Back-dilution water may be added at the transfer pump inlet, the base of the mixer pump, and on top of the crust.

The mixer pump will continue to be required to prevent formation of a deep nonconvective layer and resumption of BD GREs. Therefore, it is vital to ensure that the transfer and backdilution processes do not significantly degrade the pump's effectiveness. Part of the strategy to avoid mixer pump degradation is to keep the base of the crust layer well above the pump inlet, which is 236 inches above the tank bottom.

The maximum transfer for which an equal back-dilution is possible without sinking the crust is $90 \mathrm{kgal}$ if water is injected at the 96 -inch transfer pump inlet and $120 \mathrm{kgal}$ for injection at the 9-inch mixer pump burrowing ring. To keep the crust base above the lowest observed elevation of 295 inches, transfer and back-dilution must be limited to $143 \mathrm{kgal}$ and $80 \mathrm{kgal}$, respectively, for the 96 -inch back-dilution and $175 \mathrm{kgal}$ with a $112 \mathrm{kgal}$ back-dilution using the 9 -inch back-dilution elevation.

These limits can be avoided by adding water to the top of the crust to dissolve the negatively buoyant layers. If $20 \mathrm{kgal}$ of water is placed on top of the crust and the rest of the backdilution is placed under the crust, back-dilution becomes limited by crust sinking at a $128 \mathrm{kgal}$ transfer using the 96 -inch injection point and at $160 \mathrm{kgal}$ at 9 inches. The crust base remains well above the 295 -inch minimum, and crust base elevation does not limit transfer volume. This result shows that top dilution is very beneficial in providing operational flexibility to the transfer and back-dilution process. 
. 


\section{Contents}

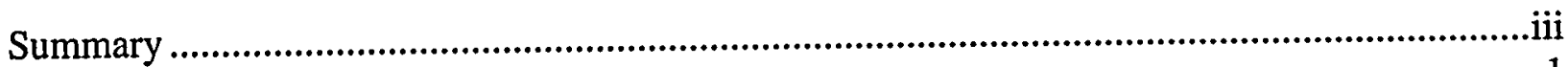

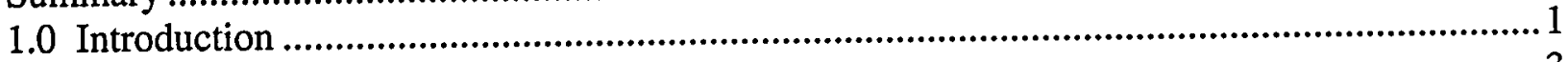

2.0 Current State of the SY-101 Crust Layer .....................................................................3

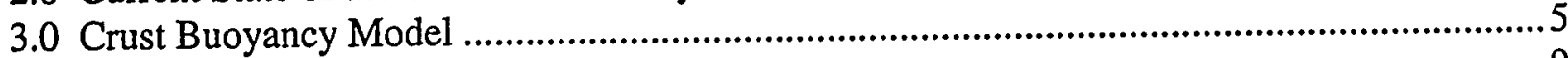

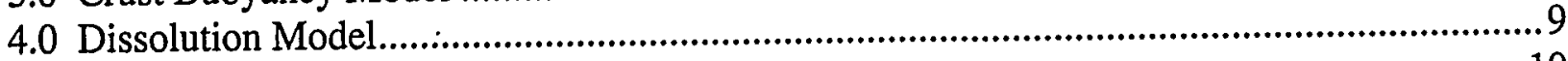

4.1 Dissolution Resulting from Low Water Addition......................................................10

4.2 Dissolution Resulting from Water Addition on Top of the Crust................................... 13

4.3. Effect of Dissolution on Crust Buoyancy................................................................. 15

5.0 Crust Response to Transfer and Back-dilution 19

5.1 Parameter Values for Current Crust Conditions ............................................................ 19

5.2 Limits on Low Water Addition............................................................................21

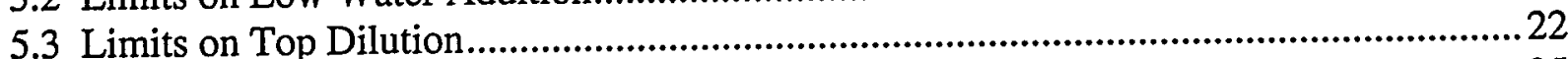

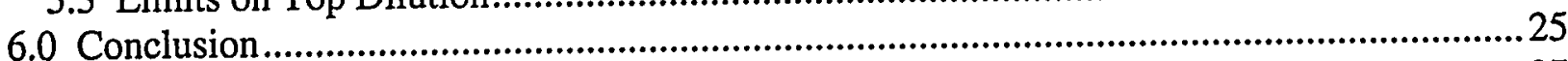

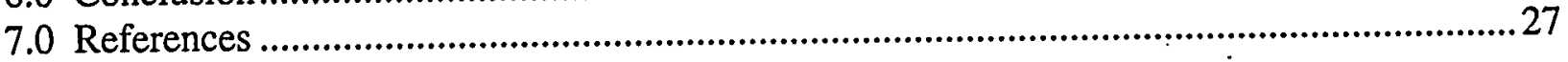

\section{Figures}

2.1 Crust Configuration as Indicated by Neutron Profiles......................................................4

2.2 Concept of Crust Configuration and Properties ..............................................................4

3.1 Detailed Crust Buoyancy Model .................................................................................5

4.1 Schematic of Back-Dilution Locations .................................................................... 10

5.1 Limitation on Low Water Addition to Prevent Crust Sinking ..........................................23

5.2 Limit on Low Water Addition after $40 \mathrm{kgal}$ Is Added to Crust Top .................................. 23

5.3 Effect of Adding Water to Crust Top after $150 \mathrm{kgal}$ Transfer ..........................................24

\section{Tables}

5.1 Crust Material Properties

5.2 Base Parameter Values for Buoyancy Model................................................................20

5.3 Base Crust Configuration 


\subsection{Introduction}

The mixer pump installed in Hanford Tank 241-SY-101 (SY-101) in July 1993 has prevented the large buoyant displacement gas release events (BD GRE) it has historically exhibited. But the absence of periodic disruption from GREs and the action of mixing have allowed the crust to grow. The accelerated gas retention has resulted in over 30 inches of waste level growth and the flammable gas volume stored in the crust has become a hazard. To remediate gas retention in the crust and the potential for buoyant displacement gas releases from below the crust, SY-101 will be diluted in the fall of 1999 to dissolve a large fraction of the solids in the tank. The plan is to transfer waste out and back-dilute with water in several steps of about 100,000 gallons each (Raymond 1999). Back-dilution water may be added at the transfer pump inlet, the base of the mixer pump, and on top of the crust.

The mixer pump will continue to be required to prevent formation of a deep nonconvective layer and resumption of BD GREs. Therefore, it is vital to ensure that the transfer and backdilution processes do not significantly degrade the pump's effectiveness. Part of the strategy to avoid mixer pump degradation is to keep the base of the crust layer well above the pump inlet, which is 236 inches above the tank bottom. ${ }^{(a)}$

Because the crust is floating, it can be modeled with simple hydrostatic principles. Most basic is that the weight of the crust must be equal to the weight of fluid displaced. The amount of crust submerged depends on the density of the fluid it displaces. For the crust to float, the specific gravity of the fluid surrounding the crust must be greater than that of the crust. During back-dilution, the fluid specific gravity in depends on how well the dilution water mixes with the mixed slurry and how the crust dissolves.

This report documents the derivation and predictions of the crust buoyancy model and the predicted crust configuration as a function of back-dilution volume and injection location. Section 2 presents our current understanding of the SY-101 crust. Section 3 derives the basic buoyancy model for crust floatation and Section 4 provides a methodology to predict the perturbations resulting from dilution both above and below the crust. Section 5 presents predictions for the first back-dilution step in SY-101. Conclusions are summarized in Section 6, and references are listed in Section 7.

(a) Lockheed Martin Hanford Company. August 18, 1999. 241-SY-101 Mixer Pump Inlet Level. Interoffice Memo 79000-99-053, RE Raymond to SY-101 Project Group. 



\subsection{Current State of the SY-101 Crust Layer}

The elevation of top of the crust is currently measured at about 432 inches above the tank bottom. Neutron and gamma probe data show that the base is at about 310 inches. The free liquid level in the tank is estimated at roughly 414 inches. These data indicate the crust is about 120 inches thick and floats on the liquid with almost two feet exposed above the liquid level. This configuration is the result of a redistribution event from mid-March through early May 1999 during which the base of the crust dropped about 30 inches concurrent with an abrupt and sustained increase in pump-induced gas releases and a gradual reversal of the level rise trend. The crust has remained approximately in its current condition since June 1999. Prior to the redistribution event, VFI (Stewart et al. 1998) and RGS (Mahoney et al. 1999) void measurements along with the first neutron/gamma profiles showed a high-void layer over a foot thick may have existed at the base of the crust. Upward migration and dispersal of the gas in this layer may explain the redistribution. Analysis indicates the average void fraction decreased as the crust thickness increased, so the total stored gas volume in the crust remained roughly constant. Neutron probe data after July 1999 show a high void layer about 10 inches thick has reformed at the new crust base level.

Recent neutron/gamma count and temperature profiles, as well as operation of the mechanical mitigation arm (MMA) in late May and penetration of the crust with the 40-inch spray lance in August, show that the crust now consists of four distinct layers. The neutron profiles are shown in Figure 2.1, and a conceptual understanding of the crust configuration is illustrated in Figure 2.2. The bottom layer (310-320 inches) consists of a high-void material that has been termed bubble slurry. It has a void fraction that may be approaching 0.6 and a relatively low yield stress, less than $100 \mathrm{~Pa}$.

The middle two-thirds (320-400 inches) is called the "paste" layer because of its expected consistency. It has a moderate void fraction, about 0.2 , that decreases with height. It is relatively strong, like stiff peanut butter or clay. Estimates of the torque required to rotate the MMA indicate a yield stress-on the order of 1000-3000 $\mathrm{Pa} .{ }^{(a)}$ The "wet clay" layer (400-414 inches) just below the liquid level has a very low void fraction, estimated at 0.08 , and is probably very strong. Though we have no direct measurements, its yield stress is assumed to be greater than $3000 \mathrm{~Pa}$. This layer may also contain old wastebergs that existed prior to mixing, though it is not clear whether they could still be distinguished from the surrounding material.

The top sixth (414-432 inches) is the porous broken material above the liquid level. Water added on the waste surface readily flows into this layer. Though individual fragments are quite strong and brittle, this layer has no strength as a unit. The height of vertical ledges visible after dissolution by flush water and estimated resistance to the cruciform lance penetration in August $1999^{\left({ }^{(a)}\right.}$ indicate a local yield stress greater than $10,000 \mathrm{~Pa}$.

(a) Wells BE and G Terrones. October 1999. PNNL Letter Report TWS99.60, Estimates of the Yield Stress in Shear of the Floating Crust Layer in Tank 241-SY-101. Pacific Northwest National Laboratory, Richland, Washingon. 


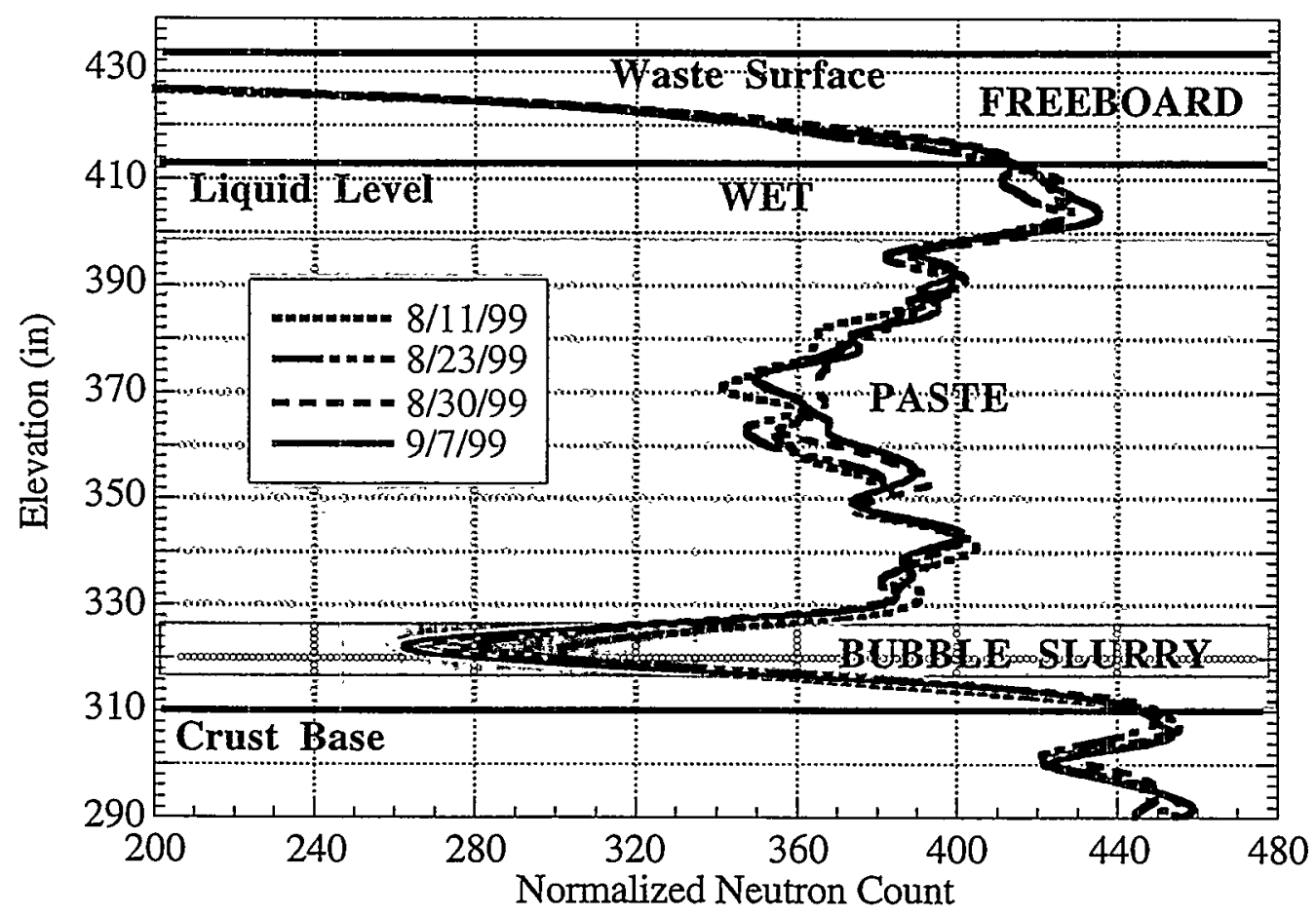

Figure 2.1. Crust Configuration as Indicated by Neutron Profiles

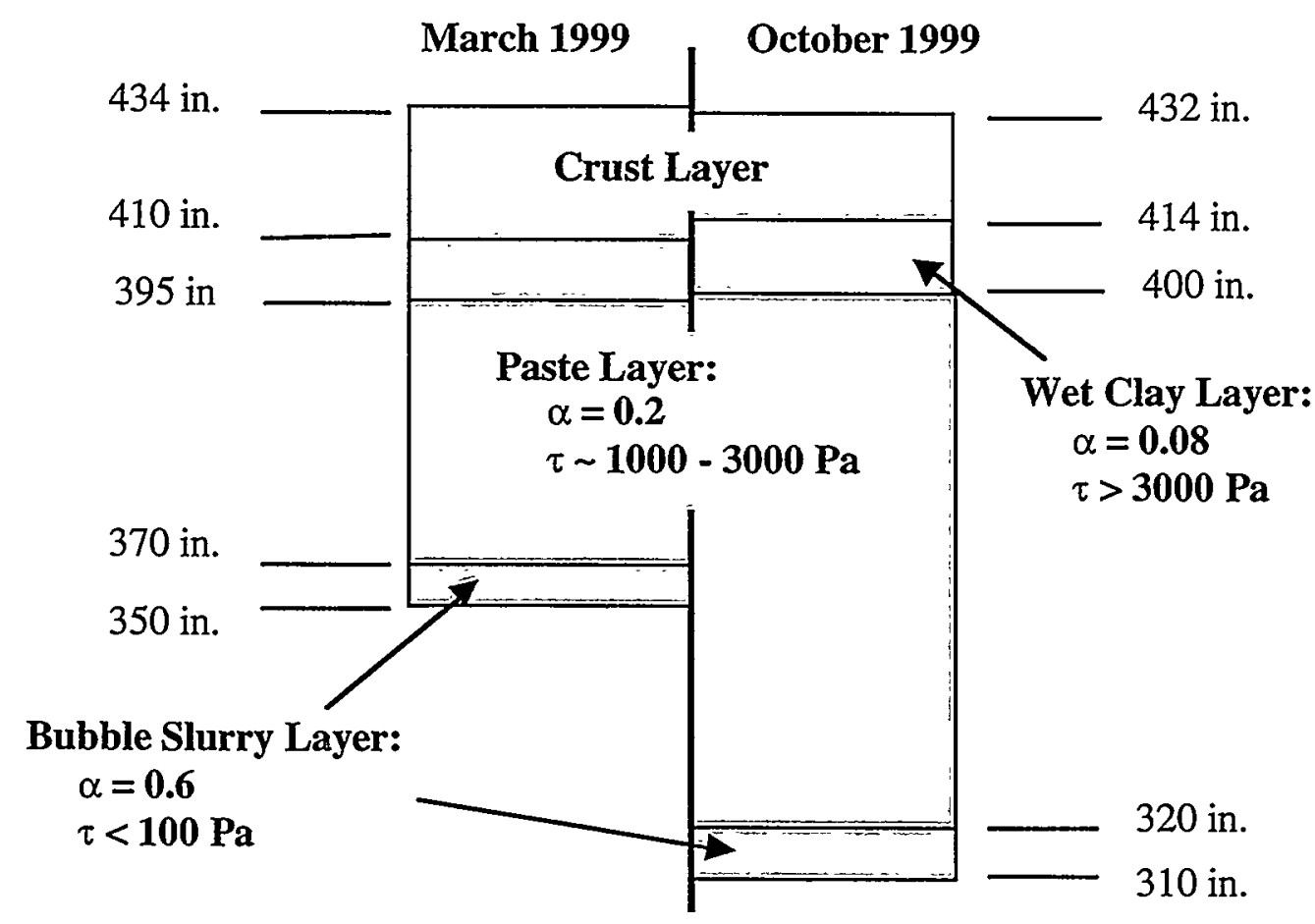

Figure 2.2. Concept of Crust Configuration and Properties 


\subsection{Crust Buoyancy Model}

The crust buoyancy model uses basic hydrostatics to establish the floating configuration of the crust. This model is illustrated in Figure 3.1. Gas is assumed to be retained in the submerged portion of the crust as particle-displacing bubbles of void fraction $\alpha_{\mathrm{c}}$. The pores between particles are assumed to be completely saturated with liquid. The overall density of the submerged material is $p_{c}$, which depends on the void fraction, the solids volume fraction in the crust, $\phi_{C}$, and the liquid and solid phase densities, $\rho_{\mathrm{L}}$ and $\rho_{\mathrm{S}}$, by the expression

$$
\rho_{C}=\left(1-\alpha_{c}\right)\left[\phi_{C} \rho_{s}+\left(1-\phi_{C}\right) \rho_{L}\right]
$$

Likewise, the density of the mixed slurry, $\rho_{S L}$, on which the crust floats depends on the void fraction, solids volume fraction, and phase densities in that layer. It is defined by

$$
\rho_{\mathrm{SL}}=\left(1-\alpha_{\mathrm{SL}}\right)\left[\phi_{\mathrm{SL}} \rho_{\mathrm{S}}+\left(1-\phi_{\mathrm{SL}}\right) \rho_{\mathrm{L}}\right]
$$

All pores and void spaces in the exposed freeboard portion of the crust are assumed open to the headspace and therefore contain the headspace atmosphere. The exposed crust contains relatively large open spaces of volume fraction $\alpha_{F}$, which may or may not be equal to $\alpha_{C}$. The solid crust material surrounding the void spaces has porosity $\omega_{\mathrm{F}}$. The pore spaces, but not the voids, are subject to capillary action and are partially filled with liquid at an average saturation of $\psi\left(\psi=1\right.$ implies the pores are filled with liquid). The overall density of the exposed crust is $\rho_{F}$, which is related to the other quantities by

$$
\rho_{F}=\left(1-\alpha_{F}\right)\left[\omega_{F} \psi \rho_{L}+\left(1-\omega_{F}\right) \rho_{S}\right]
$$

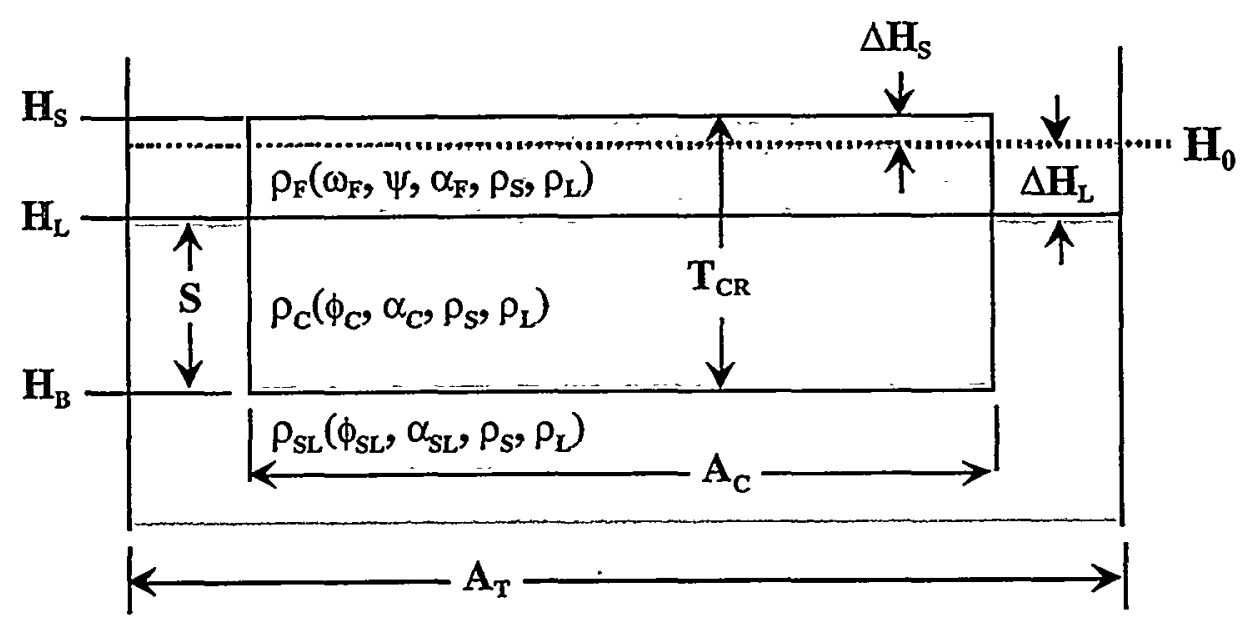

Figure 3.1. Detailed Crust Buoyancy Model 
Each of these parameters represents an average estimate over the exposed crust freeboard. While there is considerable uncertainty in determining the open spaces, they must be modeled to accurately represent crust buoyancy and to account for the significant volume of diluent mixture that flows into them. The fraction of the crust freeboard, $\Omega_{F}$, that is open (not liquid or solid) is defined as

$$
\Omega_{F}=\left(1-\alpha_{F}\right) \omega_{F}(1-\psi)+\alpha_{F}
$$

To determine the elevations of the waste surface and free liquid level, we define a reference level, $\mathrm{H}_{0}$, as the height the liquid would attain with the entire crust just submerged. In this hypothetical state, the liquid level matches the crust surface level and the crust thickness is equal to the submergence. The reference level includes all the effects of gas retention in the crust as well as in the slurry below it. However, the reference state is not in mechanical equilibrium.

To reach buoyant equilibrium, the crust rises a distance $\Delta \mathrm{H}_{\mathrm{S}}$ from the reference level and the liquid falls a distance $\Delta \mathrm{H}_{\mathrm{L}}$ to fill in the reduced submerged volume. At the same time, the excess liquid in the open volume of the portion that will become unsubmerged drains out, which slightly decreases the fall in liquid level. We wish to find an expression $\Delta \mathrm{H}_{\mathrm{L}}$ in order to compute the liquid level, crust surface level, and crust base elevation according to

$$
\begin{aligned}
& \mathrm{H}_{\mathrm{L}}=\mathrm{H}_{0}-\Delta \mathrm{H}_{\mathrm{L}} \\
& \mathrm{H}_{\mathrm{S}}=\mathrm{H}_{\mathrm{L}}+\mathrm{T}_{\mathrm{CR}}-\mathrm{S} \\
& \mathrm{H}_{\mathrm{B}}=\mathrm{H}_{\mathrm{L}}-\mathrm{S}
\end{aligned}
$$

The solution for $\Delta \mathrm{H}_{\mathrm{L}}$ is based on conservation of liquid mass for the process of going from the reference state to buoyant equilibrium. This is expressed as

$$
\Delta \mathrm{H}_{\mathrm{L}}\left(\mathrm{A}_{\mathrm{T}}-\mathrm{A}_{\mathrm{C}}\right)=\mathrm{A}_{\mathrm{C}} \Delta \mathrm{H}_{\mathrm{S}}-\mathrm{A}_{\mathrm{C}}\left(\Delta \mathrm{H}_{\mathrm{S}}+\Delta \mathrm{H}_{\mathrm{L}}\right) \Omega_{\mathrm{F}}
$$

where $A_{T}$ and $A_{C}$ are the tank and crust cross-sectional areas, respectively. The crust area is unknown but must be less than the tank area. It is most convenient to include the areas as a ratio, $\mathrm{A}_{C} / \mathrm{A}_{\mathrm{T}}$. Rearranging and applying the identity $\Delta \mathrm{H}_{\mathrm{S}}=\mathrm{T}_{\mathrm{CR}}-\mathrm{S}-\Delta \mathrm{H}_{\mathrm{L}}$, Eq. (3.6) becomes

$$
\Delta \mathrm{H}_{\mathrm{L}}=\frac{\mathrm{A}_{\mathrm{C}}}{\mathrm{A}_{\mathrm{T}}}\left(\mathrm{T}_{\mathrm{CR}}-\mathrm{S}\right)\left(1-\Omega_{\mathrm{F}}\right)
$$

If we apply Archimedes' principle, the total weight of the crust must equal the weight of slurry it displaces. The weight per unit area of both the exposed and submerged portions of the crust need to be included separately:

$$
S \rho_{C}+\left(T_{C R}-S\right) \rho_{D}=S \rho_{S L}
$$

where the densities are defined by Eq. (3.1), (3.2), and (3.3).

Solving for the submergence yields 


$$
\mathrm{S}=\mathrm{T}_{\mathrm{CR}} \frac{\rho_{\mathrm{F}}}{\rho_{\mathrm{F}}+\rho_{\mathrm{SL}}-\rho_{\mathrm{C}}}
$$

The reference level includes the in situ volume of gas retained both in the crust and in the layers below the crust:

$$
\mathrm{H}_{0}=\mathrm{h}_{0}+\frac{\mathrm{V}_{\mathrm{GSL}}}{\mathrm{A}_{\mathrm{T}}}+\frac{\mathrm{V}_{\mathrm{GC}}}{\mathrm{A}_{\mathrm{T}}}
$$

where $h_{0}$ is the degassed waste level with all solids submerged, $V_{G S L}$ is the in situ gas volume in the slurry layer below the crust, and $V_{G C}$ is the in situ gas volume in the crust. Because the crust is assumed submerged at the reference level, the effect of gas in the crust must be distributed over the entire surface area. The volume of gas in the crust can be expressed in terms of the submergence and void fraction as

$$
\mathrm{V}_{\mathrm{GC}}=\alpha_{\mathrm{C}} \mathrm{SA}_{\mathrm{C}}
$$

The gas in the slurry layer can be similarly computed by assigning a void fraction, $\alpha_{\mathrm{SL}}$, for which the non-gas volume is the total degassed volume less the degassed volume of the crust. The result is

$$
\mathrm{V}_{\mathrm{GSL}}=\frac{\alpha_{\mathrm{SL}}}{1-\alpha_{\mathrm{SL}}}\left[\mathrm{h}_{0} \mathrm{~A}_{\mathrm{T}}-\left(1-\alpha_{\mathrm{C}}\right) S \mathrm{~A}_{\mathrm{C}}-\left(1-\Omega_{\mathrm{F}}\right)\left(\mathrm{T}_{\mathrm{CR}}-\mathrm{S}\right) \mathrm{A}_{\mathrm{C}}\right]
$$

Combining Eq. (3.10), (3.11), and (3.12) provides the final expression for the reference level:

$$
\mathrm{H}_{0}=\mathrm{h}_{0}+\alpha_{\mathrm{C}} \mathrm{S} \frac{\mathrm{A}_{\mathrm{C}}}{\mathrm{A}_{\mathrm{T}}}+\frac{\alpha_{\mathrm{SL}}}{1-\alpha_{\mathrm{SL}}}\left[\mathrm{h}_{0}-\left(1-\alpha_{\mathrm{C}}\right) \mathrm{S} \frac{\mathrm{A}_{\mathrm{C}}}{\mathrm{A}_{\mathrm{T}}}-\left(1-\Omega_{\mathrm{F}}\right)\left(\mathrm{T}_{\mathrm{CR}}-\mathrm{S}\right) \frac{\mathrm{A}_{\mathrm{C}}}{\mathrm{A}_{\mathrm{T}}}\right]
$$

The sequence of steps required to determine the free liquid level, waste surface level, and crust base elevation is

1. Determine the submergence with Eq. (3.9)

2. Find $\Delta \mathrm{H}_{\mathrm{L}}$ using Eq. (3.7)

3. Calculate the reference level, $\mathrm{H}_{0}$, with Eq. (3.13)

4. Compute $\mathrm{H}_{\mathrm{L}}, \mathrm{H}_{\mathrm{S}}$ and $\mathrm{H}_{\mathrm{B}}$ via Eq. (3.5a), (3.5b), and (3.5c), respectively. 



\subsection{Dissolution Model}

After waste from the mixed slurry layer is transferred out of SY-101 into SY-102, water will be added both on top of and below the crust layer. The back-dilution scheme is sketched in Figure 4.1. Water will be placed on top of the crust through a flush line in the transfer pump pit. The water will fall 15-20 ft to the waste surface. Because the water is much less dense than the liquid surrounding the crust, it will flow out across the tank over the liquid level, eventually filling the open space in the current freeboard. Because the water will flow through the freeboard in intimate contact with the solids, we expect dissolution of the freeboard layer to be relatively rapid (on the order of a day). Dissolution depth is expected to be slightly greater in the vicinity of the water addition but still relatively uniform because of the barrier of the heavier saltsaturated liquid below.

Water will be added under the crust through the in-line dilution system, at the inlet of the transfer pump eight feet off the tank bottom. Since water is much lighter than the slurry, it will rise immediately as a plume, mixing with the slurry as it goes. Mixing above the injection point is predicted to be very effective (Antoniak and Meyer 1999) with little stratification. The solids suspended in the slurry are quite small and will dissolve rapidly in contact with the water. A one-micron particle is $99 \%$ dissolved in less than one second assuming pure diffusion. Diffusion alone will dissolve $99 \%$ of a 10 -micron particle or $90 \%$ of a 100 -micron particle in about a minute (Cussler 1984).

Essentially no mixing or dissolution is expected in the layer of slurry below the water injection point unless the mixer pump is run. Even then, mixing will be limited if a large density gradient has formed. However, there is also provision for adding water through the "burrowing ring" at the base of the mixer pump. The nozzles in the burrowing ring exit through holes in the bottom velocity plate at 9 inches off the tank bottom. (a) Adding water at this elevation ensures that essentially all of the soluble suspended solids in the entire slurry layer will be dissolved if sufficient water is added. The additional solids that may be present in the 50-60-inch loosely settled layer at the tank bottom are ignored.

Solids dissolution is calculated under the basic assumption that soluble solids will dissolve until the liquid mixture of dissolved solids and water are in equilibrium. The mass of dilution water required to dissolve a given mass of solids is then equal to the product of the solids mass to be dissolved, the fraction of the solids that are soluble, and ratio of the mass of water to the mass of dissolved solids in the saturated liquid.

(a) LMHC Interoffice Memo 79000-99-053, from RE Raymond to the SY-101 Project Group, August 18, 1999. Subject: 241-SY-101 Mixer Pump Inlet Level, and SY-101 mixer pump drawing H2-89953. 


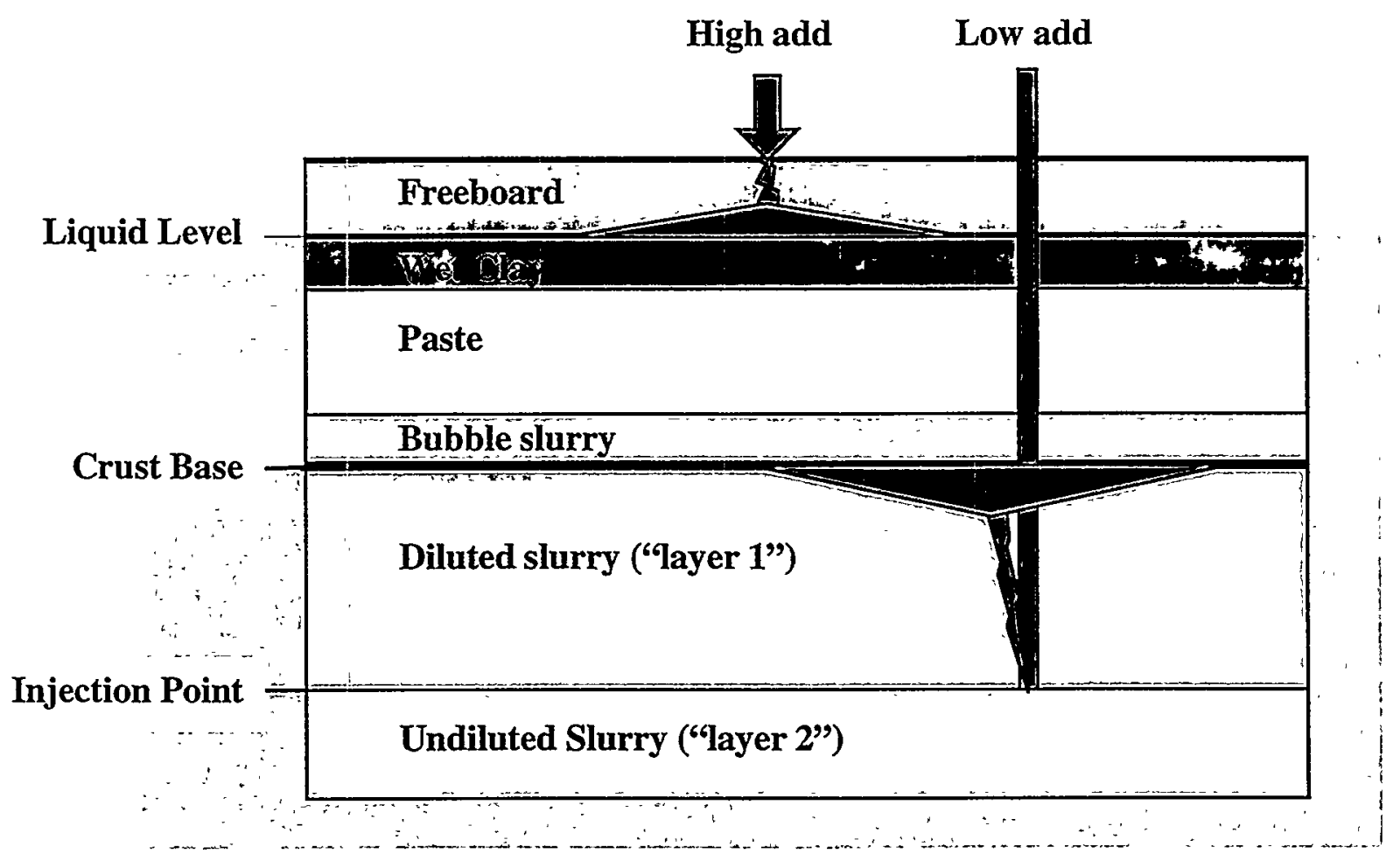

Figure 4.1. Schematic of Back-Dilution Locations

Based on a statistical interpretation of SY-101 waste dilution data, the saturated liquid contains about 0.79 grams of water for every gram of dissolved solids at tank temperature. The solids mass is calculated based on a density of $2200 \mathrm{~kg} / \mathrm{m}^{3}$ for both undissolved and dissolved solids as well as the insoluble solids which compose about $40 \%$ of the total solids mass. ${ }^{(a)}$ Water density is assumed to be $1000 \mathrm{~kg} / \mathrm{m}^{3}$. The resulting density of the saturated liquid at tank temperature is $1485 \mathrm{~kg} / \mathrm{m}^{3}$. Specific assumptions and calculational models for dissolution due to low and top water addition are described in Sections 4.1 and 4.2, respectively. Calculation of the buoyancy of the resulting crust is derived in Section 4.3.

\subsection{Dissolution Resulting from Low Water Addition}

As stated above, the mixed slurry layer is assumed to contain a uniform suspension of solid particles and gas bubbles. Dissolution is assumed to occur only above the water injection point. The slurry above the injection point is Layer " 1 ," and the undiluted slurry below is Layer "2". Water is assumed to dissolve soluble solids above the injection point until it reaches saturation or until all available solids are dissolved. Insoluble particles are assumed to remain in

(a) Kuhn WL and BE Wells. October 1999. PNNL Letter Report TWS00.06, Simplified Conceptual and Mathematical Model of Dilution of Tank 241-SY-101 Waste. Results are based on data given in NHC Internal Memo 82100-99-015 from Process Chemistry to NW Kirch, April 22, 1999. Subject: Dilution Studies of Tank 241-SY-101 Waste - Preliminary Results. 
suspension. Excess water available after solids are dissolved is assumed to begin dissolving the crust. Gas is assumed to be released in proportion to the fraction of soluble solids dissolved. No gas release or dissolution occurs below the injection point. Insoluble solids left as the crust dissolves from the bottom up are assumed to join the slurry.

The mass of undissolved soluble solids and saturated liquid in the existing slurry layer above the injection point is computed, respectively, by

and

$$
M_{S 1}=\left(1-\alpha_{S L}\right) \phi_{S L} \rho_{S} T_{1} A_{T}\left(1-F_{\text {insol }}\right)
$$

$$
M_{L 1}=\left(1-\alpha_{S L}\right)\left(1-\phi_{S L}\right) \rho_{L} T_{1} A_{T}
$$

where

$\alpha_{\mathrm{SL}} \quad=$ void fraction in the slurry

$\phi_{\mathrm{SL}} \quad=$ volume fraction of undissolved solids in the slurry

$\rho_{\mathrm{S}} \cdot \quad=$ density of undissolved solids $\left(2200 \mathrm{~kg} / \mathrm{m}^{3}\right)$

$\rho_{\mathrm{L}} \quad=$ density of saturated mixture of dissolved solids and water $\left(1485 \mathrm{~kg} / \mathrm{m}^{3}\right)$

$T_{1} \quad=$ thickness of Layer 1 before dissolution, including the effect of transfer $\mathrm{T}_{1}=\mathrm{T}_{10}-\mathrm{V}_{\mathrm{T}} / \mathrm{A}_{\mathrm{T}}$

$\mathrm{T}_{10} \quad=$ thickness of Layer 1 before transfer

$\mathrm{A}_{\mathrm{T}} \quad=$ tank cross-sectional area

$\mathrm{F}_{\text {insol }}=$ fraction of the total solids mass that is insoluble (40\%).

The mass of water required to dissolve the soluble solids in the slurry is calculated as described above by

$$
\mathrm{M}_{\mathrm{W} 1}=\mathrm{EM}_{\mathrm{S} 1}
$$

where $\mathrm{E}$ is the ratio of water mass to dissolved solids mass in saturated liquid ( 0.79 grams water per gram dissolved solids). The mass of soluble solids that will be dissolved by a given volume of water is expressed by

$$
\Delta \mathrm{M}_{\mathrm{S} 1}=\min \left[\mathrm{M}_{\mathrm{w} 1}, \mathrm{M}_{\mathrm{wL}}\right] / \mathrm{E}
$$

where $\mathrm{M}_{\mathrm{WL}}$ is the total mass of water added below the crust.

Any excess water available after dissolving all the soluble solids above the injection point $\left(M_{W_{L}}>M_{W_{1}}\right)$ is assumed to begin dissolving the solids in the base of the crust. Crust layers are assumed to dissolve sequentially from the bottom up, assuming sufficient water is available. Only the bubble slurry and paste layers are considered in low water addition because adding enough water to dissolve higher layers would almost certainly lower the slurry density sufficiently to sink the crust. The mass of soluble solids dissolved in the bubble slurry layer, $\Delta \mathrm{M}_{\mathrm{SB}}$, and paste layyer, $\Delta \mathrm{M}_{\mathrm{SP}}$, are calculated, respectively, as

and

$$
\Delta \mathrm{M}_{\mathrm{SB}}=\min \left[\mathrm{M}_{\mathrm{WB}}, \mathrm{M}_{\mathrm{WL}}-\mathrm{M}_{\mathrm{WI}}\right] / \mathrm{E}
$$




$$
\Delta \mathrm{M}_{\mathrm{SP}}=\min \left[\mathrm{M}_{\mathrm{WP}}-\Delta \mathrm{M}_{\mathrm{SPH}} \mathrm{E}, \mathrm{M}_{\mathrm{WL}}-\mathrm{M}_{\mathrm{W}_{1}}-\mathrm{M}_{\mathrm{WB}}\right] / \mathrm{E}
$$

where $\Delta \mathrm{M}_{\mathrm{SPH}}$ is the mass of soluble solids in the paste layer already dissolved by top dilution, as discussed in Section 4.2. $\mathrm{M}_{\mathrm{WB}}$ and $\mathrm{M}_{\mathrm{WP}}$ are the water masses required to dissolve solids in the two layers. The water mass is computed from the solids mass by applying Eq. (4.3). The mass of undissolved soluble solids, $\mathrm{M}_{\mathrm{SC}}$, and saturated liquid, $\mathrm{M}_{\mathrm{LCi}}$, in crust layer $\mathrm{i}$ are given, respectively, by

$$
M_{S C i}=\rho_{S} T_{i} A_{T} \frac{A_{C}}{A_{T}}\left(1-\alpha_{i}\right) \phi_{C}\left(1-F_{i n s o l}\right)
$$

and

$$
M_{L C i}=\rho_{L} T_{i} A_{T} \frac{A_{C}}{A_{T}}\left(1-\alpha_{i}\right)\left(1-\phi_{C}\right)
$$

where

$\alpha_{i} \quad=$ void fraction in crust layer $i$

$\phi_{\mathrm{C}} \quad=$ volume fraction of undissolved solids in the crust

$\mathrm{T}_{\mathrm{i}} \quad=$ thickness of crust layer $\mathrm{i}$ before dissolution

$\mathrm{A}_{\mathrm{C}} / \mathrm{A}_{\mathrm{T}}=$ fraction of tank cross sectional area occupied by crust.

Besides the masses given by Eq. (4.7) and (4.8), solids and liquid also exist in the slurry that is assumed to surround the submerged crust below the freeboard. The contribution of the surrounding slurry is expressed as

$$
M_{S S i}=\rho_{S} T_{i} A_{T}\left(1-\frac{A_{C}}{A_{T}}\right)\left(1-\alpha_{S L}\right) \phi_{S L}\left(1-F_{i n s o l}\right)
$$

for the soluble solids and

$$
M_{L S i}=\rho_{L} T_{i} A_{T}\left(1-\frac{A_{C}}{A_{T}}\right)\left(1-\alpha_{S L}\right)\left(1-\phi_{S L}\right)
$$

The total mass of soluble solids, insoluble solids, and liquid in the submerged crust layers is the sum of that given by the sum of Eq. (4.7) and (4.9) and the sum of Eq. (4.8) and (4.10), respectively:

and

$$
\mathrm{M}_{\mathrm{Si}}=\mathrm{M}_{\mathrm{SCi}}+\mathrm{M}_{\mathrm{SSi}}
$$

$$
\mathrm{M}_{\mathrm{Li}}=\mathrm{M}_{\mathrm{LCi}}+\mathrm{M}_{\mathrm{LSi}}
$$

The mass of insoluble solids in crust layer i and associated slurry can be calculated directly from the soluble mass and insoluble fraction as

$$
\mathrm{M}_{\mathrm{ISi}}=\mathrm{M}_{\mathrm{Si}} \mathrm{F}_{\text {insol }} /\left(1-\mathrm{F}_{\text {insol }}\right)
$$

The assumption that mixed slurry surrounds the crust is conservative. The passages available to fluid flow around the crust are believed to be narrow, and the action of the mixer pump would not be expected to push particles up into them. The solids volume fraction around 
the crust is apparently not affected by the mixer pump because the waste level does not rise during pump runs. Gas bubbles, however, are expected to rise up through these passages on their way to the tank headspace. Including bubbles but not particles in the liquid around the crust would reduce the crust mass necessary to create the observed submergence depth and freeboard height. Assuming particles are present has the effect of overpredicting water addition by about $10 \%$.

The fraction of crust layer i remaining after dissolution and the mass of formerly interstitial liquid and insoluble solids freed by the dissolution are assumed proportional to the fraction of soluble solids mass dissolved. The void fraction, solids volume fractions, and other properties of the remaining undissolved material are assumed to remain unchanged at their original values. The decrease in layer thickness, $\Delta \mathrm{T}_{\mathrm{i}}$, is determined by

$$
\Delta \mathrm{T}_{\mathrm{i}}=\mathrm{T}_{\mathrm{i}} \frac{\Delta \mathrm{M}_{\mathrm{Si}}}{\mathrm{M}_{\mathrm{Si}}}
$$

The mass of interstitial liquid, $\Delta \mathrm{M}_{\mathrm{Li}}$, and of insoluble solids, $\Delta \mathrm{M}_{\mathrm{JS}}$, freed from crust layer $\mathrm{i}$ by dissolution are similarly given by

$$
\begin{aligned}
& \Delta M_{L i}=M_{L i} \frac{\Delta M_{S i}}{M_{S i}} \\
& \Delta M_{I S i}=M_{I S i} \frac{\Delta M_{S i}}{M_{S i}}=\Delta M_{S i} \frac{F_{\text {insol }}}{1-F_{\text {insol }}}
\end{aligned}
$$

The freed insoluble solids plus the liquid mixture consisting of the dissolved solids and freed interstitial liquid from crust dissolution along with the added water are assumed to mix completely with the diluted waste in the slurry above the water injection point. No mixing is assumed to occur with the slurry below the injection point. Calculations for dissolution by water addition on top of the crust are shown in the next section.

\subsection{Dissolution Resulting from Water Addition on Top of the Crust}

Dissolution of the upper crust layers is assumed to proceed similarly to dissolution of the lower layers. Layers are assumed to dissolve sequentially from the top down. The water is assumed to dissolve all the soluble solids available in the top layer first, and only the excess water is available to begin dissolving the next layer down. The top dilution model considers the freeboard, wet clay, and paste layers. The calculations for the latter two layers follow those described above for dissolution of the bubble slurry and paste layers from bottom dilution. The solids and interstitial liquid mass are determined by Eq. (4.7) through (4.13) and the amount of water required to dissolve the soluble solids by applying Eq. (4.3) to the layer being considered. 
Because it is above the liquid level, the freeboard layer is a special case. Its properties differ from the layers below, and it is not surrounded by mixed slurry. The soluble solids and interstitial liquid mass in the freeboard layer is computed, respectively, by

$$
M_{S F}=\left(1-\alpha_{F}\right)\left(1-\omega_{F}\right) \rho_{S} T_{F}\left(\frac{A_{C}}{A_{T}}\right) A_{T}\left(1-F_{\text {insol }}\right)
$$

and

$$
M_{L F}=\left(1-\alpha_{F}\right) \omega_{F} \psi \rho_{L} T_{F}\left(\frac{A_{C}}{A_{T}}\right) A_{T}
$$

where $\alpha_{\mathrm{F}} \quad=$ void fraction (volume fraction of large voids) in the freeboard

$\omega_{\mathrm{F}} \quad=$ porosity of the non-void region (which is subject to capillary action)

$\psi \quad=$ average liquid saturation in the non-void fraction due to capillary action (the porosity is filled with liquid when $\psi=1$ )

$\mathrm{T}_{\mathrm{F}} \quad=$ thickness of the freeboard layer before dissolution.

The overall fraction of the freeboard that is open, not solid or liquid, can be computed as

$$
\Omega_{\mathrm{F}}=\left(1-\alpha_{\mathrm{F}}\right) \omega_{\mathrm{F}}(1-\psi)+\alpha_{\mathrm{F}}
$$

The soluble solids mass in the freeboard that is dissolved by high water addition is calculated similarly to Eq. (4.4) as

$$
\Delta \mathrm{M}_{\mathrm{SF}}=\min \left[\mathrm{M}_{\mathrm{WF}}, \mathrm{M}_{\mathrm{WH}}\right] / \mathrm{E}
$$

where $M_{W H}$ is the total volume of water added on top of the crust, and $M_{W F}$ is the mass of water required to dissolve the soluble solids in the entire freeboard $\left(M_{W F}=E M_{S F}\right)$. Any excess water available after the entire freeboard layer is dissolved begins to dissolve the wet clay layer and paste layer in sequence. The mass of each that dissolves is expressed, respectively, as follows:

and

$$
\Delta \mathrm{M}_{\mathrm{SC}}=\min \left[\mathrm{M}_{\mathrm{wC}}, \mathrm{M}_{\mathrm{WH}}-\mathrm{M}_{\mathrm{WF}}\right] / \mathrm{E}
$$

$$
\Delta M_{S P}=\min \left[M_{W P}, M_{W H}-M_{W F}-M_{W c}\right] / E
$$

where $M_{W P}$ and $M_{W C}$ are the mass of water needed to dissolve the soluble solids in the paste and wet clay layers, calculated as $\mathrm{EM}_{\mathrm{SP}}$ and $\mathrm{EM}_{\mathrm{SC}}$, respectively. The solids and liquid mass of the two non-freeboard layers are computed with Eq. (4.7) through (4.13).

The thickness of the crust layers remaining after dissolution and the mass of formerly interstitial liquid and insoluble solids freed by the dissolution are assumed proportional to the fraction of the total soluble solids mass dissolved. The void fraction, solids volume fractions, and other properties of the remaining undissolved material are assumed to remain unchanged at their original values. The decrease in layer thickness is determined by Eq. (4.14), the mass of interstitial liquid freed by Eq. (4.15), and the freed insoluble solids by Eq. (4.16). 
The liquid mixture, consisting of the dissolved solids and freed interstitial liquid from crust dissolution along with the added water, is assumed to flow down through the crust and mix completely with the diluted waste in the slurry above the water injection point along with any liquid created by dissolution of the lower crust layers by low addition. The insoluble solids freed by dissolution are conservatively assumed to remain as added weight on top of the crust. The model to calculate the effects of dissolution and mixing on crust buoyancy is described in Section 4.3.

\subsection{Effect of Dissolution on Crust Buoyancy}

To determine whether the remaining crust will continue to float after dilution, we must compare the average crust density to that of the liquid in which it must float. The remaining crust density is computed by summing up the remaining mass and dividing by the remaining volume. The remaining crust volume is given by the following expression:

$$
\begin{aligned}
\mathrm{V}_{\mathrm{CR}}= & \mathrm{A}_{\mathrm{T}} \frac{\mathrm{A}_{\mathrm{C}}}{\mathrm{A}_{\mathrm{T}}}\left[\left(1-\frac{\Delta \mathrm{T}_{\mathrm{F}}}{\mathrm{T}_{\mathrm{F}}}\right) \mathrm{T}_{\mathrm{F}}\left(1-\Omega_{\mathrm{F}}\right)+\left(1-\frac{\Delta \mathrm{T}_{\mathrm{C}}}{\mathrm{T}_{\mathrm{C}}}\right) \mathrm{T}_{\mathrm{C}}+\left(1-\frac{\Delta \mathrm{T}_{\mathrm{P}}}{\mathrm{T}_{\mathrm{P}}}\right) \mathrm{T}_{\mathrm{P}}+\left(1-\frac{\Delta \mathrm{T}_{\mathrm{B}}}{\mathrm{T}_{\mathrm{B}}}\right) \mathrm{T}_{\mathrm{B}}\right] \\
& +\frac{\left(\Delta \mathrm{M}_{\mathrm{ISF}}+\Delta \mathrm{M}_{\mathrm{ISC}}+\Delta \mathrm{M}_{\mathrm{ISP}}\right)}{\rho_{\mathrm{SD}}}
\end{aligned}
$$

where $T_{i}$ is the original layer thickness, $\Delta T_{i}$ is the change in thickness due to dissolution calculated by Eq. (4.9), $\Omega_{\mathrm{F}}$ is the fraction of the freeboard that is not solid or liquid from Eq. (4.14) and $\rho_{\mathrm{SD}}$ is the density of dissolved solids. The last term on the right side of Eq. (4.23) represents the volume of the insoluble solids freed by dissolution resulting from water added on top of the crust that are assumed to remain on top. These masses are calculated by Eq. (4.16). The insoluble mass from the paste layer is only that part produced by top dilution.

The mass of the remaining crust is computed as the product of the original layer mass, excluding the surrounding slurry, and the ratio of the remaining layer thickness to the original thickness plus the mass of insoluble solids remaining on top of the crust. This is expressed by

$$
\begin{aligned}
\mathrm{M}_{\mathrm{CR}} & =\left(1-\frac{\Delta \mathrm{T}_{\mathrm{F}}}{\mathrm{T}_{\mathrm{F}}}\right)\left(\frac{\mathrm{M}_{\mathrm{SCF}}}{\left(1-\mathrm{F}_{\text {insol }}\right)}+\mathrm{M}_{\mathrm{LCF}}\right)+\left(1-\frac{\Delta \mathrm{T}_{\mathrm{C}}}{\mathrm{T}_{\mathrm{C}}}\right)\left(\frac{\mathrm{M}_{\mathrm{SCC}}}{\left(1-\mathrm{F}_{\text {insol }}\right)}+\mathrm{M}_{\mathrm{LCC}}\right) . \\
+ & +\left(1-\frac{\Delta \mathrm{T}_{\mathrm{p}}}{\mathrm{T}_{\mathrm{P}}}\right)\left(\frac{\mathrm{M}_{\mathrm{SCP}}}{\left(1-\mathrm{F}_{\text {insol }}\right)}+\mathrm{M}_{\mathrm{LCP}}\right)+\left(1-\frac{\Delta \mathrm{T}_{\mathrm{B}}}{\mathrm{T}_{\mathrm{B}}}\right)\left(\frac{\mathrm{M}_{\mathrm{SCB}}}{\left(1-\mathrm{F}_{\text {insol }}\right)}+\mathrm{M}_{\mathrm{LCB}}\right) \\
& +\Delta \mathrm{M}_{\mathrm{ISF}}+\Delta \mathrm{M}_{\mathrm{ISC}}+\Delta \mathrm{M}_{\mathrm{ISP}}
\end{aligned}
$$

where the original freeboard mass of soluble solids and interstitial liquid is given by Eq. (4.17) and (4.18), and the original masses of the submerged layers, excluding the surrounding slurry, is 
computed from Eq. (4.7) and (4.8). Division of the soluble solids mass by (1- $\left.\mathrm{F}_{\text {insol }}\right)$ gives the total solids mass. Again, only the insoluble solids mass freed from the paste layer due to top dilution is included in Eq. (4.24). That part freed by dissolution from the bottom up is assumed to mix with the slurry.

Finally, the average density of the remaining crust is simply the remaining mass divided by the remaining volume:

$$
\rho_{\mathrm{CR}}=\frac{\mathrm{M}_{\mathrm{CR}}}{\mathrm{V}_{\mathrm{CR}}}
$$

The density of the slurry must exceed the density of the remaining crust computed by Eq. (4.25) for the crust to float. The slurry density after transfer and back-dilution results from the combination of 1 ) the original slurry liquid and solid mass above the water injection point, 2) dilution water added above and below, 3) dissolved solids and freed interstitial liquid and insoluble solids from crust dissolution, and 4) the reduction in volume from gas release due to dissolution of slurry solids above the water injection point. However, if the liquid from dissolving the crust is lighter than the slurry after dilution, it will remain above the slurry and no mixing will occur. Therefore we compute the slurry density in two steps, the first including only the effects of dilution and gas release and the second adding the effect of flowdown and mixing of the liquid portion of the dissolved crust.

Before flowdown of dissolved crust, the volume of the slurry above the injection point, $V_{s 1}$, is the sum of the fraction of the original slurry volume that did not dissolve, the volume of the water added to the slurry that did not dissolve crust, and the volume of the dissolved solids and associated liquid. We conservatively assume at this point that the insoluble crust solids released by bottom dissolution have not yet joined the slurry. This sum can be expressed as

$$
\mathrm{V}_{1}=\mathrm{A}_{\mathrm{T}}\left(1-\frac{\Delta \mathrm{M}_{\mathrm{S} 1}}{\mathrm{M}_{\mathrm{S} 1}}\right) \mathrm{T}_{1}+\frac{\Delta \mathrm{M}_{\mathrm{S} 1}}{\rho_{\mathrm{SD}}}+\frac{\Delta \mathrm{M}_{\mathrm{IS} 1}}{\rho_{\mathrm{S}}}+\frac{\Delta \mathrm{M}_{\mathrm{L} 1}}{\rho_{\mathrm{L}}}+\frac{\mathrm{M}_{\mathrm{W} 1}}{\rho_{\mathrm{W}}}
$$

where $\Delta M_{S 1}, \Delta M_{I S 1}$ and $M_{S 1}$ defined by Eq. (4.4), (4.16) and (4.1), respectively; $T_{1}$ is the thickness of the slurry layer above the injection point after transfer but before back-dilution; $\Delta \mathrm{M}_{\mathrm{Ll}}=$ $\mathrm{M}_{\mathrm{L} 1} \Delta \mathrm{M}_{\mathrm{SI}} / \mathrm{M}_{\mathrm{S} 1}$ with $\mathrm{M}_{\mathrm{L} 1}$ from Eq. (4.2); and $\mathrm{M}_{\mathrm{W} 1}=\mathrm{EM}_{\mathrm{SI}}$. The corresponding total mass, $\mathrm{M}_{1}$, is the sum of the original solids and liquid mass above the injection point and the water added:

$$
\mathrm{M}_{1}=\mathrm{M}_{\mathrm{S} 1}+\mathrm{M}_{\mathrm{S} 1}+\mathrm{M}_{\mathrm{L} 1}+\mathrm{M}_{\mathrm{W} 1}
$$

The density of the slurry before flowdown of the dissolved crust is mass divided by the volume:

$$
\rho_{1}=\frac{M_{1}}{V_{1}}
$$

After flowdown, the volume and mass of the dissolved solids and freed liquid from both the crust and surrounding slurry along with the insoluble solids freed by dissolution of the 
bottom crust layers and the total water added above the crust are added to $V_{1}$ and $M_{1}$. The new volume, mass, and density after flowdown are given by the following equations, respectively:

$$
\begin{aligned}
\mathrm{V}_{1 \mathrm{~F}}= & \mathrm{V}_{1}+\frac{\Delta \mathrm{M}_{\mathrm{SF}}+\Delta \mathrm{M}_{\mathrm{SC}}+\Delta \mathrm{M}_{\mathrm{SP}}+\Delta \mathrm{M}_{\mathrm{SB}}}{\rho_{\mathrm{SD}}}+\frac{\Delta \mathrm{M}_{\mathrm{ISP}}+\Delta \mathrm{M}_{\mathrm{ISB}}}{\rho_{\mathrm{S}}} \\
+ & \frac{\Delta \mathrm{M}_{\mathrm{LF}}+\Delta \mathrm{M}_{\mathrm{LC}}+\Delta \mathrm{M}_{\mathrm{LP}}+\Delta \mathrm{M}_{\mathrm{LB}}}{\rho_{\mathrm{L}}}+\frac{\mathrm{M}_{\mathrm{WH}}+\mathrm{M}_{\mathrm{WL}}-\mathrm{M}_{\mathrm{W} 1}}{\rho_{\mathrm{W}}} \\
\mathrm{M}_{1 \mathrm{~F}}= & \mathrm{M}_{1}+\Delta \mathrm{M}_{\mathrm{SF}}+\Delta \mathrm{M}_{\mathrm{SC}}+\Delta \mathrm{M}_{\mathrm{SP}}+\Delta \mathrm{M}_{\mathrm{SB}}+\Delta \mathrm{M}_{\mathrm{ISP}}+\Delta \mathrm{M}_{\mathrm{ISB}} \\
+ & \Delta \mathrm{M}_{\mathrm{LF}}+\Delta \mathrm{M}_{\mathrm{LC}}+\Delta \mathrm{M}_{\mathrm{LP}}+\Delta \mathrm{M}_{\mathrm{LB}}+\mathrm{M}_{\mathrm{WH}}+\mathrm{M}_{\mathrm{WL}}-\mathrm{M}_{\mathrm{W} 1} \\
& \rho_{1 \mathrm{~F}}=\frac{\mathrm{M}_{\mathrm{IF}}}{\mathrm{V}_{\mathrm{IF}}}
\end{aligned}
$$

The densities of Eq. (4.28) and (4.31) assume perfect mixing between the base of the crust and the water injection point. However, mixing will not be perfect, and some degree of stratification will form. Antoniak and Meyer (1999) simulated the low back-dilution process using the TEMPEST code. The simulations predicted very good mixing with only a slight density gradient between the injection point and the crust base. This effect is conservatively included by assuming complete stratification rather than a smooth gradient. The stratification is modeled by multiplying the mixed densities by a factor equal to the ratio of the minimum to the maximum slurry densities predicted by the simulations. The minimum specific gravity computed below the crust after adding $100 \mathrm{kgal}$ of water at the transfer pump inlet was 1.52 and the maximum was 1.56 . This makes the stratification factor equal to $1.52 / 1.56=0.97$.

Including the stratification effect, the crust remaining after dilution/dissolution is predicted to float if the following condition is met:

$$
\rho_{\mathrm{CR}}<0.97 \cdot \min \left(\rho_{1}, \rho_{\mathrm{IF}}\right)
$$

Assuming the crust remains floating after dilution and flowdown of the dissolved solids, we must determine whether the crust base remains above the mixer pump inlet. Conservatively assuming that the crust is floating with zero freeboard, the level of the crust base is

$$
\mathrm{H}_{\mathrm{B}}=\mathrm{T}_{2}+\mathrm{V}_{\mathrm{IF}} / \mathrm{A}_{\mathrm{T}} \text {. }
$$

Where $T_{2}$ is the thickness of the undiluted slurry layer below the injection point. The total crust thickness, $T_{C R}$, remaining after dissolution and flowdown is

$$
\mathrm{T}_{\mathrm{CR}}=\mathrm{T}_{0}-\Delta \mathrm{T}_{\mathrm{F}}-\Delta \mathrm{T}_{\mathrm{C}}-\Delta \mathrm{T}_{\mathrm{P}}-\Delta \mathrm{T}_{\mathrm{B}}
$$

where $T_{0}$ is the original crust thickness. The insoluble solids left on top of the crust are not included in the thickness calculation. 
. 


\subsection{Crust Response to Transfer and Back-Dilution}

As stated in the introduction, we wish to avoid any transfer and back-dilution scenario that would cause the crust to sink. At the same, time we must allow sufficient water to be added under the crust to raise it well away from the mixer pump inlet should its operation degrade significantly. This section applies the buoyancy and dissolution models to find limits on transfer and/or back-dilution volume that will satisfy these conditions. Input parameter values for the buoyancy and dissolution models are established in Section 5.1. Section 5.2 parametrically investigates the maximum volume of low water addition that will not sink the crust as a function of transfer volume. The effects of top dilution for a $150-\mathrm{kgal}$ initial transfer are studied in Section 5.3.

\subsection{Parameter Values for Current Crust Conditions}

The first task in determining the effects of dilution on crust buoyancy is to establish the current condition and properties of the crust. The material properties of the crust mixed slurry have been reasonably well established by ball rheometer measurements (Stewart et al. 1995) and core samples (Reynolds 1993). Data from recent dissolution experiments on 1998 core samples were also interpreted to provide consistent values at tank temperature. ${ }^{\text {(a) }}$ These data are summarized in Table 5.1.

Reasonable estimates for the remaining parameters were developed by comparing the buoyancy model results to a series of measured levels. Table 5.2 lists data for specific dates for which input values are known with some confidence. The unknown parameters were adjusted to give the best match with the measured waste levels. The last column summarizes the best

Table 5.1. Crust Material Properties

\begin{tabular}{|c|l|}
\hline Solids specific gravity - undissolved & 2.2 \\
\hline " - dissolved & 2.2 \\
\hline Liquid specific gravity & 1.49 \\
\hline Fraction of solids mass that is insoluble & 0.4 \\
\hline $\begin{array}{c}\text { Crust submerged solids volume fraction } \\
\text { (results in a crust degassed specific gravity of 1.75) }\end{array}$ & 0.36 \\
\hline $\begin{array}{l}\text { Mixed slurry solids volume fraction } \\
\text { (results in a slurry degassed specific gravity of 1.60) }\end{array}$ & 0.15 \\
\hline
\end{tabular}

(a) Kuhn WL and BE Wells. October 1999. PNNL Letter Report TWS00.06, Simplified Conceptual and Mathematical Model of Dilution of Tank 241-SY-101 Waste. Results are based on data given in NHC Internal Memo 82100-99-015 from Process Chemistry to NW Kirch, April 22, 1999. Subject: Dilution Studies of Tank 241-SY-101 Waste - Preliminary Results. 
estimate values for the parameters to be used in modeling current conditions. Measured values are shown in bold. The crust thickness was determined from temperature profiles from validation probe runs in the multifunction instrument trees. The crust and slurry void fractions were obtained from the void fraction instrument (Stewart et al. 1998) or RGS (Mahoney et al. 1999). ${ }^{\text {(a) }}$ The measured waste surface level was assumed to be the value indicated by the Enraf ${ }^{\circledast}$ buoyancy gauge in riser $002(1 \mathrm{~A})$. The liquid level was taken to be the value read on the Enraf in riser 001 (1C) after a water flush.

When the best estimate values from Table 5.2 are applied with the current crust thickness, levels, and estimated void fractions, the basic crust buoyancy model derived in Section 3 provides a description of the current crust configuration. The results are summarized in Table 5.3. The measured waste levels for mid-June 1999 match the predictions well. The crust is just over $3 \mathrm{~m}$ thick and $86 \%$ submerged. It has an average void fraction of about 0.23 , which has been divided into the four layers described in Section 2. The bulk slurry void fraction is estimated as 0.027 from the mixer pump volute pressure trend. Two inches have been added to the degassed level to account for the approximately 2000 gallons of water added during operation of the mechanical mitigation $\operatorname{arm}^{(\mathrm{b})}$ in May and in lancing and installation of the transfer pump in August 1999.

Table 5.2. Base Parameter Values for Buoyancy Model

\begin{tabular}{|c|c|c|c|c|}
\hline$\overline{\text { Date }}$ & $7 / 19 / 98$ & 9/22/98 & $2 / 8 / 99$ & Best \\
\hline Event & VFI & VFI & RGS & Estimate \\
\hline Crust thickness $(\mathrm{cm})$ & 150 & 155 & 200 & \\
\hline Crust submerged void fraction & 0.3 & 0.32 & 0.34 & \\
\hline Mixed slurry void fraction & 0.013 & 0.015 & 0.025 & \\
\hline Crust freeboard void fraction & 0.34 & 0.34 & 0.34 & 0.34 \\
\hline Crust freeboard porosity & 0.42 & 0.42 & 0.42 & 0.42 \\
\hline Crust freeboard saturation & 0.6 & 0.6 & 0.6 & 0.6 \\
\hline Crust area fraction & 0.86 & 0.86 & 0.86 & 0.86 \\
\hline Degassed level $(\mathrm{cm})$ & 994.5 & 994.5 & 994.5 & 994.5 \\
\hline \multicolumn{5}{|l|}{ Predicted Crust Levels (inches) } \\
\hline Surface & 415.1 & 417.4 & 428.1 & \\
\hline Liquid & 401.7 & 402.9 & 408.7 & \\
\hline \multicolumn{5}{|l|}{ Measured Levels (inches) } \\
\hline$\overline{\text { Surface }}$ & 415.5 & 418.0 & 428.0 & \\
\hline Liquid & 403.0 & 403.4 & 408.0 & \\
\hline
\end{tabular}

(a) Slurry void fractions are currently estimated from trends in the mixer pump nozzle pressure during pump runs calibrated to retained gas sampler data. The pressure is approximately proportional to fluid density, which, in turn, is proportional to the non-void fraction.

(b) Stewart CW. April 1999. Initial Operation Plan for Mechanical Crust Mitigation in Tank 241-SY-101. PNNL letter report TWS99.32, Pacific Northwest National Laboratory, Richland, Washington. 
Table 5.3. Base Crust Configuration (summer 1999)

\begin{tabular}{|c|c|l|c|}
\hline Input Values & & & \\
\hline Bulk slurry void fraction & 0.027 & Degassed level (cm) & 996.5 \\
\hline Freeboard Thickness (cm) & 50 & Freeboard Void Fraction & 0.34 \\
\hline Wet Clay Thickness (cm) & 32 & Wet Clay Void Fraction & 0.08 \\
\hline Paste Thickness (cm) & 203 & Paste Void Fraction & 0.21 \\
\hline Bubble Slurry Thickness (cm) & 25 & Bubble Slurry Void Fraction & 0.60 \\
\hline Total Crust Thickness (cm) & 310 & Avg. Submerged Void Fraction & 0.23 \\
\hline & & Measured Waste Levels (in.) & \\
\hline & & Surface (Enraf 1A) & 431 \\
\hline Computed Values & & Liquid (Enraf 1C) & 412 \\
\hline Submergence (cm) & 260 & Crust Base (in) (Neutron Probe) & 310 \\
\hline Submerged S.G. (including gas) & 1.34 & Predicted Waste Levels (in.) & \\
\hline Freeboard S.G. & 1.98 & Surface & 431 \\
\hline Average crust S.G. & 1.41 & Liquid & 412 \\
\hline Bulk slurry S.G. (including gas) & 1.55 & Crust Base & 310 \\
\hline
\end{tabular}

\subsection{Limits on Low Water Addition}

As water is added below the crust, the density of the slurry above the injection point decreases by dilution from the added water. This is partially compensated for by the release of gas assumed in proportion to the fraction of solids in the slurry that are dissolved. If there is no top dilution, the crust is unaffected until all the soluble solids are dissolved from the slurry. At this point, the excess water begins to dissolve the bubble slurry layer. Because the bubble slurry contains a disproportionately high volume of gas, dissolution of this layer greatly increases the average crust density. When this happens, the diluted slurry can no longer support the heavier crust and will sink.

In the current plan, there are two locations for low water addition: the transfer pump inlet eight feet off the tank bottom and the mixer pump burrowing ring nine inches off tank bottom. ${ }^{(a)}$ The lower the back-dilution water injection point, the larger the volume of slurry available for the water to mix with. This means that the back-dilution volume would be much less limited with water added through the mixer pump base than through the transfer pump inlet.

Increasing transfer volumes with equal back-dilution create an increasingly dilute slurry. At some point the back-dilution volume must be reduced below the transfer volume to prevent crust sinking by the mechanism described above. With less back-dilution than transfer, the crust base will begin descending as transfer volume is increased further. Transfer is finally limited to

(a) LMHC Interoffice Memo 79000-99-053 from RE Raymond to the SY-101 Project Group, August 18, 1999. Subject: 241-SY-101 Mixer Pump Inlet Level, and SY-101 Mixer Pump Drawing H2-89953. 
that volume for which the maximum back-dilution will not raise the crust base sufficiently above the mixer pump inlet to ensure effective mixing. Because the mixer pump has operated effectively with the crust base at 295 inches, we choose this level as the lower limit.

Figure 5.1 shows the maximum back-dilution volume and crust base elevation as a function of transfer volume for water addition though both the mixer pump base at 9 inches and the transfer pump inlet at 96 inches. No water is added on top of the crust. The maximum transfer for which an equal back-dilution is possible is at $90 \mathrm{kgal}$ for the 96 -inch injection point and 120 $\mathrm{kgal}$ for the 9-inch injection. Reducing the back-dilution volume enough to keep the crust from sinking lowers the crust base to the lowest observed elevation (295 inches after the April-May rearrangement described in Section 2 with a transfer volume of $143 \mathrm{kgal}$ with $80 \mathrm{kgal}$ back-dilute for the 96-inch injection point and $175 \mathrm{kgal}$ with $112 \mathrm{kgal}$ back dilute the 9-inch elevation).

These limits can be avoided by simply adding water to the top of the crust to dissolve most of the heavy freeboard and wet clay layers. These layers are negatively buoyant, and removing them makes the crust almost unconditionally positively buoyant. This is illustrated by repeating the calculations of Figure 5.1 with $20 \mathrm{kgal}$ of water placed on top and the rest of the back-dilution at the two low elevations. The result is shown in Figure 5.2. The crust base actually rises as the bubble slurry and lower paste layers dissolve. For the 96-inch water injection, back-dilution becomes limited by crust sinking at a transfer of $128 \mathrm{kgal}$. The limit is $160 \mathrm{kgal}$ for the 9-inch injection. The crust base remains well above the historic 295-inch minimum. This result shows that some significant amount of top water addition is very beneficial in providing operational flexibility to the transfer and back-dilution process.

\subsection{Limits on Top Dilution}

Crust sinking is not a concern in top dilution. As stated above, dissolving the freeboard and wet clay layers removes the negatively buoyant portion of the crust. Further dissolution of the paste layer from the top down further decreases the average crust density, even to the point where the crust would float in pure water (the bubble slurry with an assumed void fraction of 0.6 has a bulk specific gravity of only 0.7 ).

Top dilution raises the crust even more effectively than low addition though it does not do so immediately. Even before the freeboard dissolves, water placed on top of the crust exerts a significant buoyant force that lifts the crust out of the heavier slurry. As solids in the upper layers dissolve, the density of the fluid mixture on top of the crust increases. When the mixture density exceeds the bulk density of the crust, the crust begins to float on it, and the mixture flows down to join the slurry. It is estimated that, because of the intimate contact expected between the water and solids, the freeboard layer should completely dissolve within a day. Dissolution of the currently submerged layers may require on the order of a few weeks. 


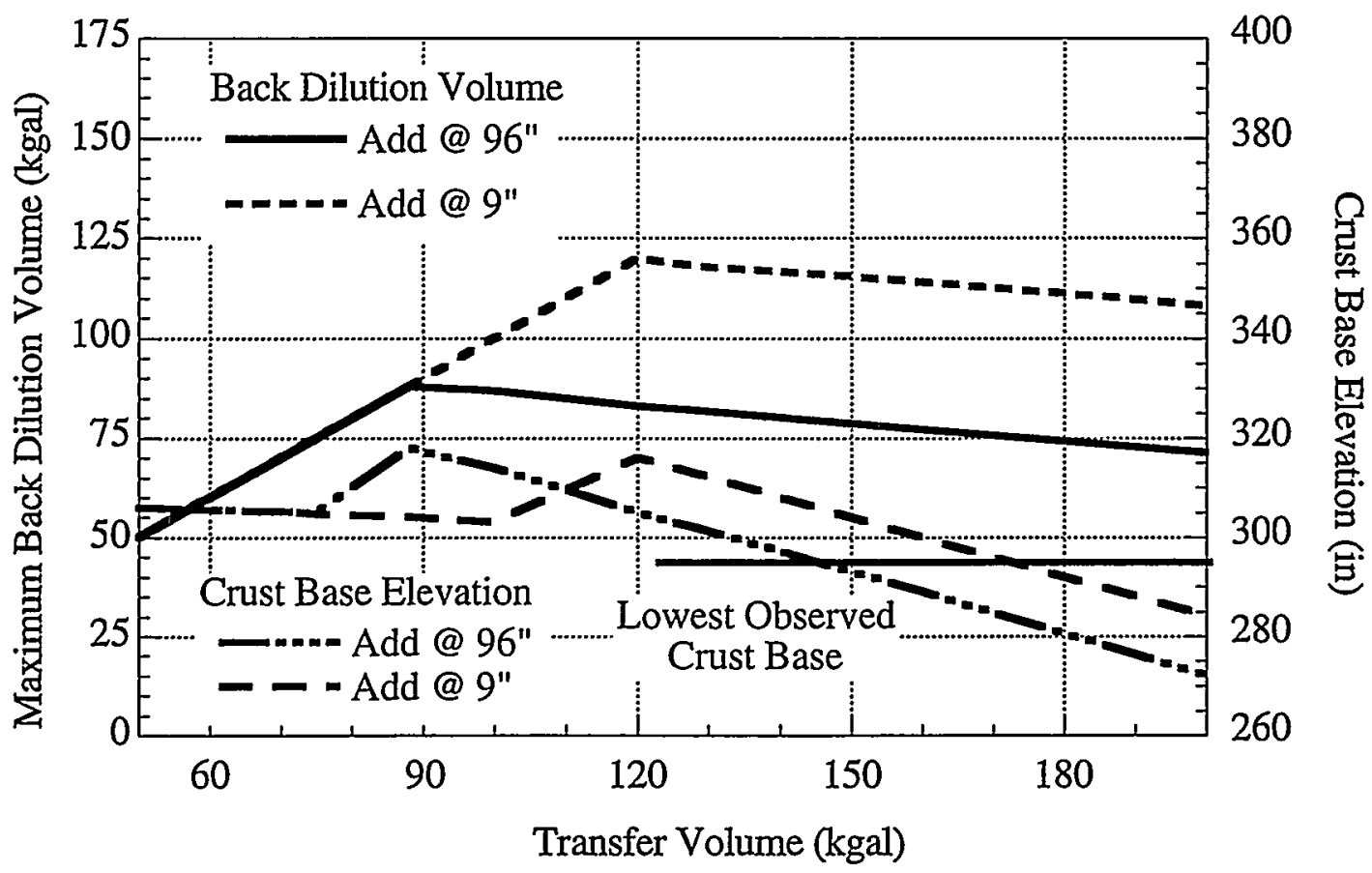

Figure 5.1. Limitation on Low Water Addition to Prevent Crust Sinking

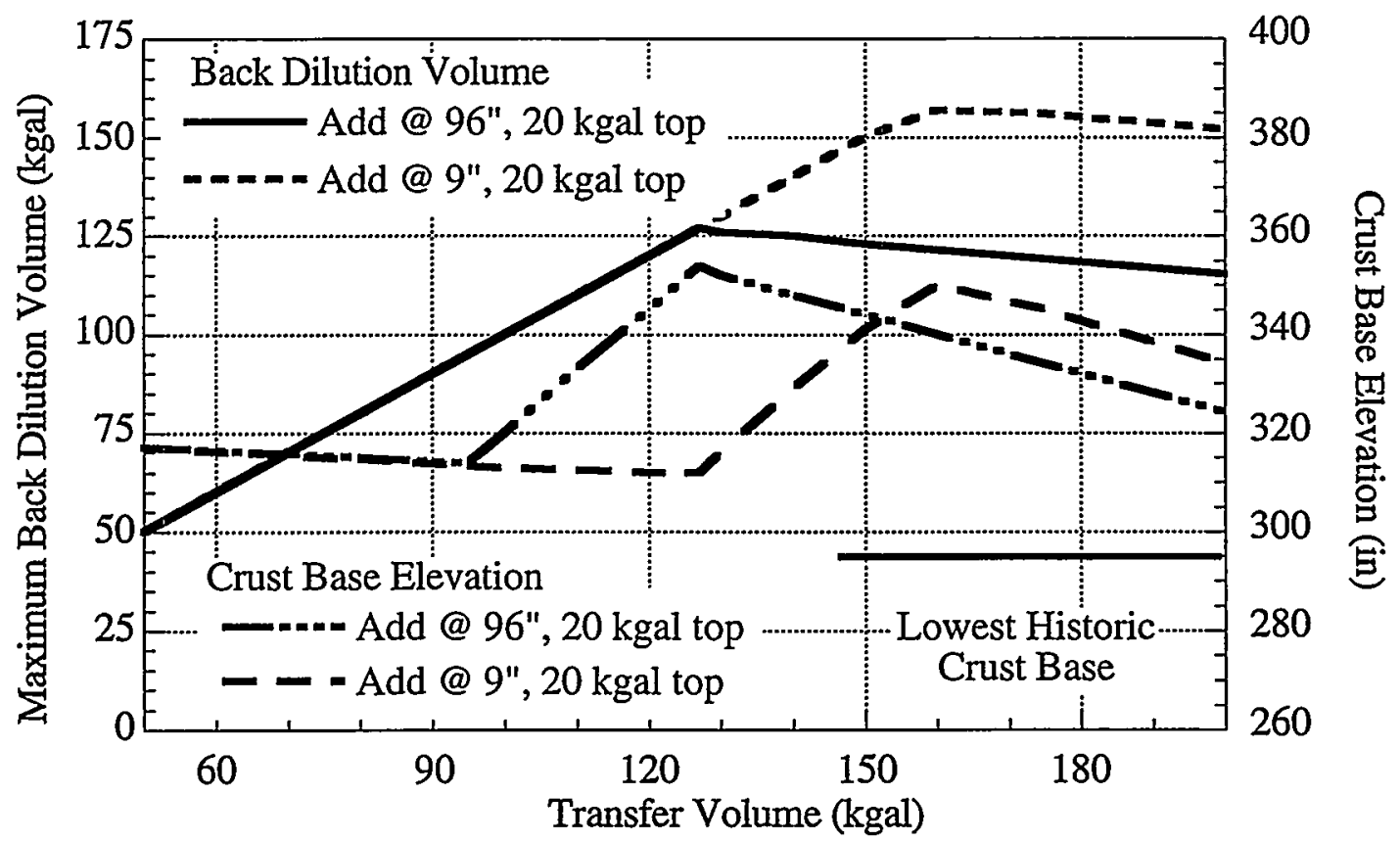

Figure 5.2. Limit on Low Water Addition after $40 \mathrm{kgal}$ Is Added to Crust Top 
The only concern that could be considered a limit to top dilution is the potential for the paste layer to be so thinned and weakened that the bubble slurry could penetrate through it to release its gas, making the tank headspace flammable. However, transferring waste out and dissolving the upper layers of the crust to the point that the bubble slurry could release greatly increases the tank headspace. If the bubble slurry thickness remains around 10 inches, and all of its gas were released suddenly, the hydrogen concentration would be just over $50 \%$ of the lower flammability limit after a transfer of $100 \mathrm{kgal}$ and less than $50 \%$ for a $150 \mathrm{kgal}$ transfer.

It has also been demonstrated that a much thinner layer than presently exists can contain the bubble slurry. During VFI and RGS measurements in the fall of 1998, a bubble slurry layer existed with a measured void fraction exceeding $50 \%$. The crust at that time was about 60 inches thick-half the current 120 inches. Of course the crust was only 30-40 inches thick for many years, but it is impossible to determine whether a bubble slurry layer also existed during that time. This experience shows that the crust can be confidently thinned to at least 60 inches without releasing the bubble slurry.

The effect of top dilution on crust thickness and crust base elevation is shown in Figure 5.3. The figure assumes a 150-kgal transfer with $30 \mathrm{kgal}$ added at the transfer pump inlet and additional volume added on top of the crust. The figure shows that about $50 \mathrm{kgal}$ can be placed on top of the crust without reducing the thickness down to the historic 60 inches. Note also that a 35-kgal top addition brings the crust level above 295 inches, and further top dilution continues to raise the crust. We conclude that there is no impediment to adding significant volumes of water on top of the crust layer.

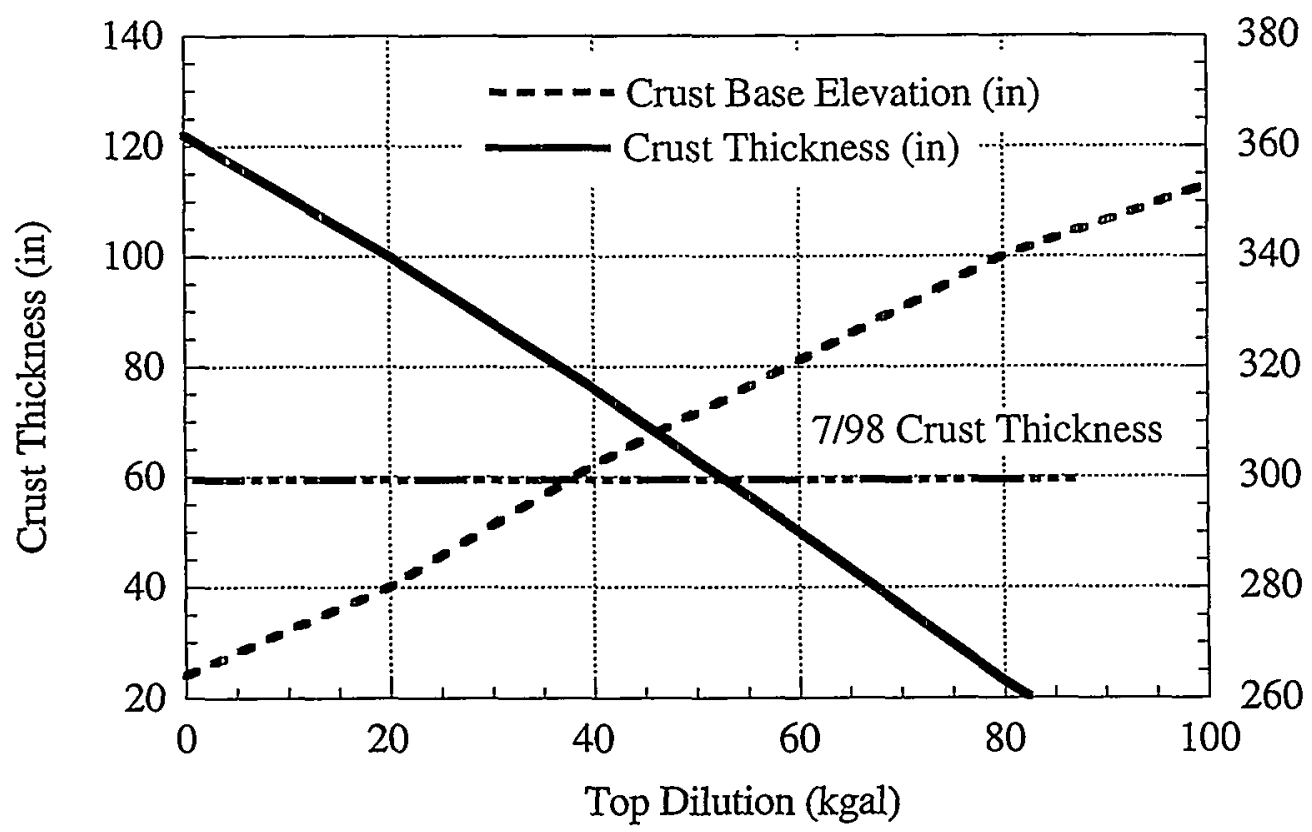

Figure 5.3. Effect of Adding Water to Crust Top after $150 \mathrm{kgal}$ Transfer 


\subsection{Conclusion}

The maximum transfer for which an equal back-dilution is possible without sinking the crust is $90 \mathrm{kgal}$ if water is injected at the 96-inch transfer pump inlet and $120 \mathrm{kgal}$ for injection at the 9-inch mixer pump burrowing ring. To keep the crust base above the lowest observed elevation of 295 inches, transfer and back-dilution must be limited to $143 \mathrm{kgal}$ and $80 \mathrm{kgal}$, respectively, for the 96 -inch back-dilution and $175 \mathrm{kgal}$ with a $112 \mathrm{kgal}$ back-dilution using the 9 -inch back-dilution elevation.

These limits can be avoided by adding water to the top of the crust to dissolve the negatively buoyant layers. If $20 \mathrm{kgal}$ of water is placed on top of the crust and the rest of the backdilution is placed under the crust, back-dilution becomes limited by crust sinking at a $128 \mathrm{kgal}$ transfer using the 96 -inch injection point and at $160 \mathrm{kgal}$ at 9 inches. The crust base remains well above the 295 -inch minimum, and crust base elevation does not limit transfer volume. This result shows that top dilution is very beneficial in providing operational flexibility to the transfer and back-dilution process.

There is no serious impediment to adding large volumes of water on top of the crust layer. Recent history shows that the crust can be confidently thinned to 60 inches without releasing bubble slurry. This requires approximately $50 \mathrm{kgal}$ of top dilution. Even if the entire bubble slurry layer were suddenly released to the headspace, the hydrogen concentration would be just above $50 \%$ of the LFL after a $100 \mathrm{kgal}$ transfer and under $50 \%$ of the LFL after a $150 \mathrm{kgal}$ transfer.

We conclude that with proper planning a $150 \mathrm{kgal}$ transfer and an equal back-dilution can be accomplished in the fall of 1999 without danger of sinking the crust or releasing gas from the bubble slurry. The greatest margin of safety is achieved if most of the back-dilution water is placed on top of the crust. 

-1_ _ _ 


\subsection{References}

Antoniak ZI and PA Meyer. 1999. Potential Waste Stratification from Back-Dilution in Tank 241-SY-101. PNNL-13038, Pacific Northwest National Laboratory, Richland, Washington.

Cussler EL. 1984. Diffusion: Mass Transfer in Fluid Systems. Cambridge University Press.

Mahoney LA, ZI Antoniak, JM Bates, and ME Dahl. 1999. Retained Gas Sampling Results for the Flammable Gas Program. PNNL-13000, Pacific Northwest National Laboratory, Richland, Washington.

Raymond RE. 1999. Tank 241-SY-101 Surface-Level-Rise Remediation Project Plan. HNF-3824 Rev. 0, Lockheed Martin Hanford Corporation, Richland, Washington.

Stewart CW, JM Alzheimer, G Chen, and PA Meyer. 1998. In Situ Void Fraction and Gas Volume in Hanford Tank 241-SY-101 as Measured with the Void Fraction Instrument. PNNL-12033, Pacific Northwest National Laboratory, Richland, Washington. 


\section{Distribution}

No. of

Copies

Offsite

2 Office of Scientific and Technical Information

\section{Onsite}

3 DOE Richland Operations Office

CA Groendyke (3)

H6-60

\section{PHMC Team}

WB Barton

R2-11

RE Bauer

JR Biggs

RJ Cash

JM Conner

JM Grigsby

GD Johnson

S7-07

S7-73
No. of

Copies

NW Kirch

R2-11

LJ Kripps

S7-73

RE Raymond

S7-70

DA Reynolds

R2-11

18 Pacific Northwest National Laboratory

JM Bates

$\mathrm{K} 7-15$

SQ Bennett

K7-90

JW Brothers (3)

K9-20

WL Kuhn

$\mathrm{K} 7-15$

LA Mahoney

K7-15

PA Meyer

$\mathrm{K} 7-15$

SD Rassat

K6-28

CW Stewart (3)

K7-15

BE Wells

K7-15

Information Release (5)

K1-06 